\title{
Perception of the Educational Environment by Medical Students Undergoing a Curricular Transition in Kuwait
}

\author{
Manal Bouhaimed $^{a, b} \quad$ Lukman Thalib $^{a} \quad$ Suhail A.R. Doi ${ }^{c}$ \\ Departments of a Community Medicine, ${ }^{b}$ Surgery and ${ }^{\mathrm{C}}$ Medicine, Kuwait University, Kuwait
}

\author{
Key Words \\ Problem-based learning • Educational environment • \\ Undergraduate medical education - Curricular changes • \\ Kuwait
}

\begin{abstract}
Objective: The aim of this study was to measure the students' perceptions of the educational environment in a medical school undergoing curricular transition from a traditional to a problem-based learning ( $\mathrm{PBL}$ ) program in the academic year 2006-2007. Materials and Methods: The Dundee Ready Education Environment Measure (DREEM) was used to evaluate perception of the educational environment. Multivariate logistic regression models were used to identify the factors related to educational environment perception that differ between students following a traditional curriculum to those following a PBL program at Kuwait University Medical School. Results: Mean DREEM score was $53 \%$. When students moved from the traditional curriculum to the PBL system, Academic Self-Perception deteriorated, while Perception of Atmosphere improved. Academic SelfPerception deteriorated because conventional strategies of learning were perceived as no longer useful, while Perception of Atmosphere improved because of increased relevance of the studies. Conclusion: Our findings suggest that curricular changes require careful planning and thinking, with particular attention upon how they influence the educational climate. When new teaching strategies are introduced, new factors that may lead students to develop an
\end{abstract}

\section{KARGER \\ Fax +4161306 1234 \\ E-Mail karger@karger.ch}

www.karger.com
(C) 2009 S. Karger AG, Basel

$1011-7571 / 09 / 0183-0204 \$ 26.00 / 0$

Accessible online at:

www.karger.com/mpp adverse perception of their educational environment may be introduced as well. Identification of such factors can lead to an improved educational outcome.

Copyright $\odot 2009$ S. Karger AG, Basel

\section{Introduction}

Historically, didactic lectures were the medium of transfer of cognitive information to learners in medical education, and it was assumed that the learner would assimilate the knowledge taught through these lectures to become competent in applying the information learned in practice [1]. In contrast, problem-based learning (PBL) was designed to incorporate several educational strategies that would optimize student-centered learning outcomes beyond just knowledge acquisition. It emerged in the late 80 s and early 90 s due to problems in building the appropriate competencies in medical graduates exposed to didactic teaching, but its rapid acceptance was propelled more by the rapid explosion of biomedical information than by the drive to improve the students' ability to reason and communicate [2].

Despite the inherent advantages of the PBL system for learning outcomes [3-5], students' perceptions of the PBL system may not be entirely positive. This is simply because they are familiar with traditional methods of instruction used prior to medical school, and may thus feel threatened in a different system [6]. When transitioning to a PBL system students might feel, at least initially, that 
they do not know what they should be learning [6]. In the group sessions, they may have to work quite hard and be involved in different activities than just sitting and taking notes in a lecture. They may also worry about their performance in the group where all the students have different knowledge and skills. Thus, students might find it harder to manage their new independent learning tasks that have to be done differently to what they used to do.

Only by understanding these barriers, as they are perceived by students experiencing a change in their educational climate, can effective PBL-based modifications to curricula be designed that are likely to be successful in promoting high-quality learning [7]. We therefore aimed to measure the students' perception of their educational environment, using the 50-item Dundee Ready Education Environment Measure (DREEM) [8], and to compare the educational environment as perceived by the students following the traditional system with that of the newly introduced PBL system.

\section{Materials and Methods}

\section{Context}

The study population comprised of 127 first- and 105 secondyear undergraduate students in the Faculty of Medicine, Kuwait University, who are currently facing a period of transition from traditional methods of instruction to a PBL system. The first batch of students was enrolled in the new system in the academic year 2005-2006. In the PBL system, the students are encouraged to take responsibility for their own learning mixed with a traditional teaching delivery for some core curriculum in year 1 . Since the educational climate strongly affects student achievement, satisfaction and success, it is important to get feedback from students on how they experience the change from the traditional environment in the 1st year to the PBL system in year 2. In year 1, the students complete a didactic program in core basic medical subjects like biology, biophysics, biostatistics, epidemiology and chemistry. In year 2, they undergo teaching of system blocks, each of 8 weeks duration, carried out in a PBL fashion following Maastricht models [9]. Students are given a trigger at the beginning of the week and learn using the PBL process; they meet at the end of the week for wrap-up sessions. The present work was approved by the local institutional review board at the Health Sciences Center of Kuwait University, following the tenets of the Declaration of Helsinki.

\section{Participants}

A questionnaire was administered to 127 first- and $105 \mathrm{sec}$ ond-year students at the end of the academic year 2006-2007. Students in the first year were approached by 2 departmental teaching assistants after one of the behavioral sciences lectures, and were asked to voluntarily complete the questionnaire in English after explaining the purpose for data collection and stressing the anonymity of the participants. Similarly, the second-year students in the new PBL system were approached by the same teaching assistants after one of the lectures in the respiratory system module toward the end of the academic year, and asked to voluntarily complete the questionnaire. In addition to marking their response to the 50 items on the DREEM questionnaire, students were requested to indicate their year of study, nationality as well as gender. Valid returns were received from 109 first- and $93 \mathrm{sec}-$ ond-year students $(n=202)$ with response rates of 86 and $89 \%$, respectively.

\section{Instrument}

The instrument used was the 50-item DREEM, which has been found to be reliable in a range of cultural contexts since it was developed at the University of Dundee [8]. It comprises 50 items categorized under 5 domains: Students' Perception of Learning (12 items with a maximum score of 48 ); Students' Perception of Teaching (11 items with a maximum score of 44); Students' Academic Self-Perception (8 items with a maximum score 32); Students' Perception of Atmosphere (12 items with a maximum score of 48) and the Students' Social Self-Perception (7 items with a maximum score of 28). The total score for all subscales is 200. Each item is scored 0-4, with scores of 4, 3, 2, 1 and 0 assigned for strongly agree, agree, unsure, disagree and strongly disagree, respectively. Negative items were scored in a reverse order. This instrument was chosen because its psychometric performance has been found to be useful for relative comparisons [10-12]. The questions associated with the question numbers used in the Results and Discussion sections are provided in Appendix 1 .

\section{Analysis}

We statistically evaluated the differences in the educational environment and its components between the first- and secondyear students following a change in teaching strategy. Continuous variables were summarized as means and 95\% confidence intervals (CI), and an independent $t$ test was used to determine the differences in the scores between the 2 groups. Multivariate logistic regression models were used to identify the factors that were significantly different between the PBL and traditional system. Survey variables were used to identify factors likely to be associated with binary group membership of the students by year of study. All scores were continuous. The analysis was carried out initially in a multivariate fashion by inserting 1 variable in the model and then using forward stepwise regression to obtain a final model. The Wald statistic was used to test the significance of individual logistic regression coefficients for each independent variable. An overall test of model adequacy was obtained by the Hosmer and Lemeshow goodness of fit test, with an adequately fitted model being indicated by a nonsignificant $\chi^{2}$ value. Odds ratios (OR) and 95\% CI for all individual variables in the final model were estimated. All analyses were performed using SPSS version 12 (SPSS, Chicago, Ill., USA).

\section{Results}

The overall total mean DREEM score was 106/200 and the mean scores for the 5 subscales are given in table 1 . The scores ranged from $50-56 \%$ of the maximum for both the total score and each of the 5 subscale scores. In- 
Table 1. DREEM domain/overall scores per gender and academic year

\begin{tabular}{|c|c|c|c|c|c|c|}
\hline DREEM & $\begin{array}{l}\text { Perception } \\
\text { of Learning }\end{array}$ & $\begin{array}{l}\text { Perception } \\
\text { of Teaching }\end{array}$ & $\begin{array}{l}\text { Academic } \\
\text { Self-Perception }\end{array}$ & $\begin{array}{l}\text { Perception of } \\
\text { Atmosphere }\end{array}$ & $\begin{array}{l}\text { Social } \\
\text { Self-Perception }\end{array}$ & Total score \\
\hline All $(n=202)$ & $26(25.3-27.3)$ & $24(23.4-24.9)$ & $16(15.5-17.1)$ & $25(23.7-25.8)$ & $14(13.8-15.1)$ & $105 \pm 25.24$ \\
\hline Maximum possible score & 48 & 44 & 32 & 48 & 28 & 200 \\
\hline$\%$ of maximum & 54 & 55 & 50 & 52 & 50 & 053 \\
\hline Female $(\mathrm{n}=144)^{*}$ & $26(24.9-26.9)$ & $24(23.3-25.0)$ & $16(14.9-16.6)$ & $24(22.8-25.2)$ & $14(13.4-14-8)$ & $104 \pm 22.82$ \\
\hline Male $(\mathrm{n}=51)^{*}$ & $28(25.3-30.2)$ & $24(22.8-25.9)$ & $18(16.0-19.6)$ & $27(24.7-29.6)$ & $16(14.1-17.1)$ & $113 \pm 30.57$ \\
\hline $\mathrm{p}$ value & 0.106 & 0.832 & 0.024 & 0.014 & 0.040 & 0.035 \\
\hline Year $1(n=109)$ & $26(24.9-27.6)$ & $24(22.8-25.0)$ & $17(15.9-18.3)$ & $24(22.5-25.6)$ & $15(13.9-15.5)$ & $106 \pm 26.84$ \\
\hline Year $2(n=93)$ & $26(25.0-27.8)$ & $24(23.4-25.5)$ & $15(14.4-16.2)$ & $26(24.0-27.1)$ & $14(13.2-15.1)$ & $106 \pm 23.37$ \\
\hline $\mathrm{p}$ value & 0.897 & 0.465 & 0.022 & 0.174 & 0.377 & 0.965 \\
\hline
\end{tabular}

Data presented as means (8 SD, where indicated). Figures in parentheses are CI. ${ }^{*} 7$ students did not indicate their gender.

Table 2. Percentage of students scoring $\geq 75 \%$ of maximum possible score in the different DREEM domains

\begin{tabular}{llll}
\hline DREEM domains & $\begin{array}{l}\text { Lowest } \\
\text { score }\end{array}$ & $\begin{array}{l}\text { Highest } \\
\text { score }\end{array}$ & $\begin{array}{l}\text { Students scor- } \\
\text { ing } \geq 75 \% \text { of } \\
\text { max. score, } \%\end{array}$ \\
\hline $\begin{array}{c}\text { Perception of Atmosphere } \\
\quad(12 \text { questions; max. score } 48)\end{array}$ & 3 & 43 & 11 \\
$\begin{array}{c}\text { Academic Self-Perception } \\
\quad(8 \text { questions; max. score } 32)\end{array}$ & 1 & 32 & 6 \\
$\begin{array}{c}\text { Perception of Learning } \\
\quad(12 \text { questions; max. score } 48)\end{array}$ & 8 & 43 & 5 \\
$\begin{array}{c}\text { Social Self-Perception } \\
\quad(7 \text { questions; max. score } 28)\end{array}$ & 1 & 26 & 5 \\
$\begin{array}{c}\text { Perception of Teaching } \\
\quad(11 \text { questions; max. score } 44)\end{array}$ & 8 & 37 & 3 \\
\hline
\end{tabular}

dependent $t$ tests showed that the total scores were significantly lower for females compared to males, due to significantly lower scores on Academic Perception, Perception of Atmosphere and Social Self-Perception. Moreover, the Academic Perception subscale score was significantly different between years of study, being lower in year 2. Scores in the upper quartile of the subscales were highest for Perception of Atmosphere and lowest for Perception of Teaching (table 2). Multivariate forward stepwise logistic regression (table 3 ) revealed that only Academic Perception and Perception of Atmosphere were independently associated with changes in curricular strategy, with better Academic Perception in the old system, but Perception of Atmosphere being improved in the new curriculum. Female gender was overrepresented in
Table 3. Final model showing the independent and significant predictors obtained using forward stepwise logistic regression

\begin{tabular}{lllr}
\hline Variables & OR & CI & p value \\
\hline Academic Self-Perception & 0.86 & $0.79-0.93$ & $<0.001$ \\
Perception of Atmosphere & 1.10 & $1.04-1.16$ & 0.001 \\
Gender & 0.48 & $0.24-0.96$ & 0.038 \\
\hline
\end{tabular}

first-year students, and this was adjusted for in the regression model.

A detailed multivariate assessment of Academic Perception (after gender adjustment) revealed that questions $10,26,31,41$ and 45 were independently associated with the change in Academic Perception score in year 2 (questions 10 and 26: negatively associated; questions 31, 41 and 45: positively associated). Similarly, detailed multivariate assessment of Perception of Atmosphere (after gender adjustment) revealed that questions 12, 17, 23 and 34 were independently associated with the change in Perception of Atmosphere score in year 2 (question 12: negatively associated; questions 17, 23 and 34: positively associated).

When we looked in detail at Academic Perception, we found that 'Learning strategies which worked for me before continue to work for me now' and 'Last year's work had been a good preparation for this year's work' were the main determinants of the deterioration in this score. This was despite improvements in empathy, problem-solving and relevance scores. When we looked in detail at Perception of Atmosphere, we found that the main determi- 
nants of the improved score were improvements in scores for 'Cheating is a problem in this school' (reverse coded), 'The atmosphere is relaxed during lectures' and 'The atmosphere is relaxed during seminars/tutorials'. However, this was despite a deterioration in 'This school is well timetabled' scores for students in the PBL system.

\section{Discussion}

Although the total DREEM score remained the same among the first- and second-year students when they moved from the traditional curriculum to the PBL system, Academic Perception deteriorated while Perception of Atmosphere improved. Neither of these had been shown to change as students progressed through a traditional medical curriculum [13] suggesting that these changes are indeed driven by transition to the PBL system. Academic Perception may have declined because the academic potential of the students differed in the traditional and PBL systems. Nevertheless, this is unlikely since academic underachievers have not been reported to have a different Academic Perception from achievers in a medical school [12]. This suggests that when students perceive their learning strategies to have changed dramatically from one year to another, their Academic Perception could deteriorate. Students may get disappointed when the previous year's work is thought to be useless to academic achievement in consecutive years. In our case, the year 1 learning was mainly by mechanical repetition without real active critical thinking taking place.

The Perception of Atmosphere scores of our students improved because the method of delivery of instruction was relaxed and enjoyable, and students indicated that academic 'cheating' was no longer possible in the PBL system. Nevertheless, there was frustration with the students finding that the timetable was too complicated, and hence led to confusion and congestion. On further informal questioning of a nonselected group of students, it became evident that this frustration was with large chunks in the timetable allocated to self-directed learning, and students just mistook these as 'free periods'. Students felt that this self-direction, interpreted literally, was a method of learning that they needed to default to when support and guidance were substantially lacking. Although they realized that the PBL system had real gains in terms of empathy, relevance and problem-solving, they were unable to realize the benefits of these gains because of the dramatic change in learning strategy that made it difficult to cope, as well as the lack of utility of first-year learning.
Although this study has limitations (we relied on selfreports by students and could not entirely exclude interference from external factors), our results nevertheless imply a need for improvement in 2 major areas. First, the presentation of basic sciences in year 1 curriculum had emphasized the acquisition of knowledge rather than its use. With the shift in strategy in year 2, students realized rather late in the program that how they had previously learned lacked utility, and, to resolve this, they needed to change strategies to enhance the value of what they studied in year 2. This information needs to be clearly spelt out to the students at the beginning of year 2 to avoid this sort of deterioration in perception. Of course, year 1 cannot be modified because there are some basic science concepts that need to be implemented, and this is unavoidable. Second, because students perceive free periods for self-directed learning as a deterioration in 'timetabling', we suggest that 'supported' self-directed learning might be needed. This support can come in the form of guidelines for the use of such allocated time. Introducing a timetable-based study guide for the optimal timetabling of the new curricular system can resolve the frustration students feel with the scheduling in a typical PBL system, as not all students are capable of managing their learning tasks and timing well. A timetable-based guide should focus on the students' day-to-day timetables, relating the learning outcomes to each of the scheduled learning opportunities. Indeed it has been reported that such a timetable-based guide was preferred by the majority of students. It may relate to what is seen as a key function of a study guide: to lead the student through the day-to-day learning experiences in a course, to introduce to a course or a topic, and to provide an overview of what is to be achieved in their study of it [14].

\section{Conclusion}

These results strongly suggest that changes in a medical school curriculum can lead to factors that result in an adverse perception by the students of their educational climate, and that addressing such factors can lead to improvement in the educational outcome of the students. We have pointed out 2 such factors, and the task ahead is to identify other issues within the learning environment that can negatively influence the learner and take immediate action. 


\section{Appendix 1}

\section{The 50-Item DREEM Inventory}

1 I am encouraged to participate

2 The teachers are knowledgeable

3 There is a good support system for students who get stressed

4 I am too tired to enjoy this course

5 Learning strategies which worked for me before continue to work for me now

6 The teachers are patient with the patients

7 The teaching is often stimulating

8 The teachers ridicule the students

9 The teachers are authoritarian

10 I am confident about my passing this year

11 The atmosphere is relaxed during the ward teaching

12 This school is well timetabled

13 The teaching is student centered

14 I am rarely bored on this course

15 I have good friends in this school

16 The teaching is sufficiently concerned with developing my competence

17 Cheating is a problem in this school

18 The teachers have good communication skills with patients

19 My social life is good

20 The teaching is well focused

21 I am feel I am being well prepared for my profession

22 The teaching is sufficiently concerned with developing my confidence

23 The atmosphere is relaxed during lectures

24 The teaching time is put to good use

25 The teaching over-emphasizes factual learning

26 Last year's work has been a good preparation for this year's work
27 I am able to memorize all I need

28 I seldom feel lonely

29 The teachers are good at providing feedback to students

30 There are opportunities for me to develop interpersonal skills

31 I have learned a lot about empathy in my profession

32 The teachers provide constructive criticism here

33 I feel comfortable in class socially

34 The atmosphere is relaxed during seminars/tutorials

35 I find the experience disappointing

36 I am able to concentrate well

37 The teachers give clear examples

38 I am clear about the learning objectives of the course

39 The teachers get angry in class

40 The teachers are well prepared for their classes

41 My problem-solving skills are being well developed here

42 The enjoyment outweighs the stress of studying medicine

43 The atmosphere motivates me as a learner

44 The teaching encourages me to be an active learner

45 Much of what I have to learn seems relevant to a career in medicine

46 My accommodation is pleasant

47 Long-term learning is emphasized over short-term

48 The teaching is too teacher centered

49 I feel able to ask the questions I want

50 The students irritate the teachers

\section{Acknowledgements}

We gratefully acknowledge the help received from Dr. Mumtaz Shukkur and Dr. Najwa Bahnasawi of the Department of Community Medicine in data collection and data entry.

\section{References}

1 Baig LA: Problem based learning in medical education: theory, rationale, process and implications for Pakistan. J Coll Physicians Surg Pak 2006; 16:608-613.

$\checkmark 2$ Epstein RJ: Learning from the problems of problem-based learning. BMC Med Educ 2004;4:1.

-3 Distlehorst LH, Dawson E, Robbs RS, Barrows HS: Problem-based learning outcomes: the glass half-full. Acad Med 2005;80:294299.

-4 Tamblyn R, Abrahamowicz M, Dauphinée D, Girard N, Bartlett G, Grand'Maison P, Brailovsky C: Effect of a community oriented problem based learning curriculum on quality of primary care delivered by graduates: historical cohort comparison study. BMJ 2005;331:1002.
5 Burch VC, Sikakana CN, Yeld N, Seggie JL, Schmidt HG: Performance of academically at-risk medical students in a problem-based learning programme: a preliminary report. Adv Health Sci Educ Theory Pract 2007;12: 345-358.

6 Wood EJ. Problem-based learning. Acta Biochim Pol 2004;51:XXI-XXVI.

7 Mattick K, Knight L: High-quality learning: harder to achieve than we think? Med Educ 2007;41:638-644.

-8 Roff S: The Dundee Ready Educational Environment Measure (DREEM) - a generic instrument for measuring students' perceptions of undergraduate health professions curricula. Med Teach 2005;27:322-325.

$\checkmark 9$ Schmidt HG: Foundations of problem-based learning: some explanatory notes. Med Educ 1993;27:422-432.

$>10$ de Oliveira Filho GR, Vieira JE, Schonhorst L: Psychometric properties of the Dundee Ready Educational Environment Measure (DREEM) applied to medical residents. Med Teach 2005;27:343-347.
Al-Hazimi A, Zaini R, Al-Hyiani A, Hassan N, Gunaid A, Ponnamperuma G, et al: Educational environment in traditional and innovative medical schools: a study in four undergraduate medical schools. Educ Health (Abingdon) 2004;17:192-203.

12 Mayya S, Roff S: Students' perceptions of educational environment: a comparison of academic achievers and under-achievers at Kasturba Medical College, India. Educ Health (Abingdon) 2004;17:280-291.

13 Miles S, Leinster SJ: Medical students' perceptions of their educational environment: expected versus actual perceptions. Med Educ 2007;41:265-272.

14 Khogali SE, Laidlaw JM, Harden RM: Study guides: a study of different formats. Med Teach 2006;28:375-377. 